\title{
Strategies to Enhance Fat Utilisation During Exercise
}

\author{
John A. Hawley, ${ }^{1}$ Fred Brouns ${ }^{2}$ and Asker Jeukendrup ${ }^{3}$
}

1 MRC/UCT Bioenergetics of Exercise Research Unit, Department of Physiology, University of Cape Town Medical School, South Africa

2 Sandoz Nutrition Research Unit, Maastricht, The Netherlands

3 Department of Human Biology, University of Limburg, Maastricht, The Netherlands

\section{Contents}

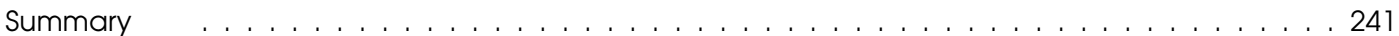

1. Fat as an Energy Source for Physical Activity . . . . . . . . . . . . . . . . . . . . . . . . . . . . 242

2. Factors Limiting Fatty Acid (FA) Uptake by Muscle Cells . . . . . . . . . . . . . . . . . . . . . . 242

3. Factors Limiting FA Oxidation by Muscle Cells . . . . . . . . . . . . . . . . . . . . . . . . . . . . . . 243

4. Techniques to Improve FA Oxidation . . . . . . . . . . . . . . . . . . . . . 244

4.1 Endurance Training . . . . . . . . . . . . . . . . . . . . . . . . . . . . . . . . 244

4.2 Caffeine Ingestion . . . . . . . . . . . . . . . . . . . . . . . . 245

4.3 L-Carnitine Ingestion . . . . . . . . . . . . . . . . . . . . . . . . . . . . 245

4.4 Medium Chain Triglyceride (TG) Ingestion . . . . . . . . . . . . . . . . . . . . . . 246

4.5 Long Chain TG Ingestion . . . . . . . . . . . . . . . . . . . . . . . . . . . . . . . . . . 247

4.6 Fat Infusion . . . . . . . . . . . . . . . . . . . . . . . . . . . . . . . . . . . . . . . . . . . 248

4.7 Fasting . . . . . . . . . . . . . . . . . . . . . . . . . . . . . . . 248

5. Effects of High Fat Diets on Exercise Performance and Metabolism . . . . . . . . . . . . . . 248

5.1 Short Term Exposure to High Fat Diets . . . . . . . . . . . . . . . . . . . . . . . . . 248

5.2 Long Term Adaptation to High Fat Diets . . . . . . . . . . . . . . . . . . . . . . . . 250

5.3 Effects of High Fat Diets on Blood Lipid Profiles and Insulin Resistance . . . . . . . . . . . . 252

6. Conclusions . . . . . . . . . . . . . . . . . . . . . . . . . . . . . . . 252

\section{Summary}

Compared with the limited capacity of the human body to store carbohydrate (CHO), endogenous fat depots are large and represent a vast source of fuel for exercise. However, fatty acid (FA) oxidation is limited, especially during intense exercise, and $\mathrm{CHO}$ remains the major fuel for oxidative metabolism. In the search for strategies to improve athletic performance, recent interest has focused on several nutritional procedures which may theoretically promote FA oxidation, attenuate the rate of muscle glycogen depletion and improve exercise capacity. In some individuals the ingestion of caffeine improves endurance capacity, but L-carnitine supplementation has no effect on either rates of FA oxidation, muscle glycogen utilisation or performance. Likewise, the ingestion of small amounts of medium-chain triglyceride (MCT) has no major effect on either fat metabolism or exercise performance. On the other hand, in endurance-trained individuals, substrate utilisation during submaximal [60\% of peak oxygen uptake $\left.\left(\mathrm{V}_{2 p e a k}\right)\right]$ exercise can be altered substantially by the ingestion of a high fat (60 to $70 \%$ of 
energy intake), low $\mathrm{CHO}$ (15 to $20 \%$ of energy intake) diet for 7 to 10 days. Adaptation to such a diet, however, does not appear to alter the rate of working muscle glycogen utilisation during prolonged, moderate intensity exercise, nor consistently improve performance. At present, there is insufficient scientific evidence to recommend that athletes either ingest fat, in the form of MCTs, during exercise, or 'fat-adapt' in the weeks prior to a major endurance event to improve athletic performance.

In the search for strategies to enhance athletic performance, recent investigations have focused on nutritional techniques which may theoretically promote fat oxidation and slow rates of muscle glycogen depletion, thereby improving exercise capacity. Such nutritional interventions include:

- ingestion of caffeine and L-carnitine

- the consumption of medium chain $\left(\mathrm{C}_{6-10}\right)$ triacyglycerol (TG) before and during exercise

- fat ingestion and fat infusions before and during exercise

- exposure to high fat, low carbohydrate (CHO) diets.

This review provides a brief summary of some of the factors that limit the utilisation of fat as an energy source for skeletal muscle during moderate intensity exercise, and describes several dietary interventions known to have an effect on substrate utilisation and athletic performance.

\section{Fat as an Energy Source for Physical Activity}

The human body utilises carbohydrate ( $\mathrm{CHO})$, fat and to a lesser extent protein, as fuel for muscular work. As an energy source, fat has several advantages over $\mathrm{CHO}$; the energy density is higher (37.5 vs $16.9 \mathrm{~kJ} / \mathrm{g}$ ) while the relative weight as stored energy is lower. On the other hand, for every gram of CHO stored as glycogen, approximately $2 \mathrm{~g}$ of water are stored. ${ }^{[1]}$ Consequently, the amount of glycogen stored in muscle and liver is limited to $\approx 450 \mathrm{~g}$. Fat can be stored in much higher amounts. In a healthy untrained male, up to $10 \mathrm{~kg}$ of fat is stored, mainly in adipose tissue. However, intramuscular fat storage is usually very small; total muscle mass may contain up to $300 \mathrm{~g}$ of fat of which the major part is stored within the myocyte as small lipid droplets. ${ }^{[2-4]}$

Both fatty acids (FA) stored in adipose tissue and fat entering the circulation after a meal can serve as potential energy sources for the muscle cell. Small but physiologically important amounts of FA are also stored as TG inside the muscle cells. FA liberated from TG stored in adipocytes are released to blood, where they are bound to albumin. Albumin levels in human blood are $\approx 6 \mathrm{mmol} / \mathrm{L}$, while levels of FA are $\approx 0.2$ to $1.0 \mathrm{mmol} / \mathrm{L}$. As albumin can maximally bind 8 FAs, ${ }^{[5]}$ the albumin transport capacity is in excess of the FA actually bound under physiological circumstances and as such, cannot be the limiting factor for FA oxidation by muscle. FA can also be derived from the TG core of circulating chylomicrons and very low density lipoproteins (VLDL), which are both formed from dietary fat in the post-absorptive state. Chylomicrons are formed in the epithelial wall of the intestine and reach the blood stream after passage through the lymphatic system. VLDL are synthesised in the liver after which they are released directly into the blood stream.

\section{Factors Limiting Fatty Acid Uptake by Muscle Cells}

During perfusion of the muscle capillaries, FA bound to albumin or stored in the core of chylomicrons and VLDL have to be released prior to transport across the vascular membrane. In the case of VLDL and chylomicrons this is achieved by the action of the enzyme lipoprotein lipase (LPL). LPL is synthesised within the muscle cell and, after an activation process, is translocated to the vascular endothelial cell membrane where it 
exerts its enzymatic action on TG. ${ }^{[6]}$ LPL also expresses phospholipase $\mathrm{A}_{2}$ activity ${ }^{[7]}$ which is necessary for the breakdown of the phospholipid surface lipid layer of the chylomicrons and lipoproteins.

LPL activity is up-regulated by caffeine, catecholamines and adenocorticotrophic hormone (ACTH), and down-regulated by insulin. ${ }^{[8-13]}$ After TG hydrolysis, most of the FA will be taken up by muscle, whereas glycerol will be taken away via the blood stream to the liver where it may serve as a gluconeogenic precursor. During the postabsorptive state the level of circulating TG in plasma is usually higher than that of FA, in contrast to the fasting state when chylomicrons are practically absent from the circulation. ${ }^{[14]}$ Nevertheless, the quantitative contribution of circulating TG to FA oxidation by the exercising muscle cells in humans is uncertain. Due to technical limitations no reliable data are available to determine whether FA derived from the TG core of VLDL or chylomicrons substantially contribute to overall FA utilisation. However, even a small extraction ratio, in the order of 2 to $3 \%$ of FA-TG, can cover over $50 \%$ of total exogenous FA uptake and subsequent oxidation. ${ }^{[15,16]}$

Arterial levels of FA strongly affect FA uptake into muscle both at rest and during low intensity exercise. ${ }^{[17-20]}$ This implies an FA gradient from blood to muscle in these conditions, ${ }^{[21]}$ which is achieved by a relatively rapid conversion of free fatty acid (FFA), taken up by the muscle cell, to fatty acyl CoA. The rate of the latter reaction is controlled by fatty acyl CoA synthetase. ${ }^{[22]}$ During transport of FA from blood to muscle, several barriers may limit FA uptake: (i) the membranes of the vascular endothelial cell; (ii) the interstitial space between endothelium and muscle cell; and (iii) the muscle cell membrane.

Uptake by endothelial cells is most likely protein mediated. Both albumin-binding protein and membrane-associated FA-binding proteins may play a role. After uptake most FA will diffuse from the luminal to the abluminal membrane of the endothelial cells as free molecules. ${ }^{[4]}$ Although minor quantities of fatty acid binding proteins (FABP) are present at this site, their role in transmembrane FA transport is assumed to be unimportant. ${ }^{[23]}$ Once in the interstitial space, albumin will bind the FA for transport to the muscle cell membrane. ${ }^{[15,21]}$ Here the FA are taken over by an FA-transporting protein, ${ }^{[24]}$ or will cross the membrane directly because of their lipophilic nature. In the sarcoplasm, FABP, which is present in relatively high levels, ${ }^{[25]}$ is crucial for FA transport to the mitochondria. This transport is not assumed to be limiting for FA oxidation.

As indicated earlier, an alternative source of FA are TGs present inside the skeletal muscle cells. For the storage of FA, glycerol is obtained from glycolysis - as glycerol-3-phosphate - which reacts with fatty acyl CoA, after which further condensation to, and storage as, TG take place in small fat droplets, mainly located in the proximity of the mitochondrial system. ${ }^{[3]}$ It has been suggested that adipocytes positioned between muscle cells may also supply FA for oxidation, but the significance of this has never been quantified. ${ }^{[4]}$ During periods of increased muscle contractile activity, muscle lipase is activated by hormonal actions which leads to the release of FA from the intramuscular TG. Whereas norepinephrine infusion has been observed to cause a significant reduction in muscle TG, ${ }^{[26]}$ insulin counteracts this effect. ${ }^{[27]}$ Apart from hormonal stimuli, there is also local muscular control of lipase activity, shown by the observation that electrical stimulation of muscle enhances TG breakdown ${ }^{\text {[28-31] }}$ Compared with fast twitch muscle fibres, slow twitch fibres have a high lipase, ${ }^{[10,32]}$ as well as TG, content. ${ }^{[33,34]}$ Interestingly, TG storage within the muscle cell can be increased by regular endurance training. ${ }^{[3,35,36]}$

\section{Factors Limiting Fatty Acid (FA) Oxidation by Muscle Cells}

At rest and during low intensity exercise, a relatively high percentage of the energy production is derived from FA oxidation. ${ }^{[17,18,37]}$ However, with increasing exercise intensities, particularly above 70 to $80 \%$ maximal oxygen uptake $\left(\mathrm{V}_{2 \max }\right)$, there 
is a progressive shift from fat to $\mathrm{CHO}^{[17,38-40]}$ indicating limitations in the rate of FA oxidation. Several explanations for this shift from fat to $\mathrm{CHO}$ have been proposed, including an increase in circulating catecholamines which stimulates both glycogen breakdown in the liver ${ }^{[41]}$ and lipolysis. However, the increased lactate formation which occurs when glycogen breakdown and glycolytic flux are increased also suppresses lipolysis. ${ }^{[42-47]}$ The net result will be a decrease in plasma FA levels and hence the supply of FA to muscle cells. As a consequence, enhanced $\mathrm{CHO}$ oxidation will most likely compensate for the reduced FA oxidation. Another reason for this substrate shift is the lower adenosine triphosphate (ATP) production rate per unit of time from fat compared with $\mathrm{CHO}$, combined with the fact that more oxygen is needed for the production of a certain amount of ATP from fat compared with $\mathrm{CHO} \cdot{ }^{[48,49]}$ Finally, limitations in the FA flux from blood to mitochondria might explain the shift from fat to $\mathrm{CHO}$ at higher exercise intensities. This flux is dependent on the level of FA in the blood, capillary density, transport capacity across vascular and muscle cell membranes, mitochondrial density and mitochondrial capacity to take up and oxidise FA. The latter depends on the action of the carnitine transport system across the mitochondrial membrane, ${ }^{[50]}$ which is regulated by malonyl CoA. ${ }^{[50-52]}$ During exercise, malonyl CoA formation is reduced and therefore the capacity to transport FA across the mitochondrial inner membrane is enhanced. ${ }^{[53]}$

The rate of FA oxidation depends on 3 processes: (i) lipolysis of TG in adipose tissue and circulating TG and transport of FA from blood plasma to the sarcoplasm; (ii) availability and rate of hydrolysis of intramuscular TG; and (iii) activation of the FA and transport across the mitochondrial membrane. It is likely that the first 2 processes pose the ultimate limitations to fat oxidation observed during conditions of maximal FA flux. This is most evident during both short term intense exercise or during the initial phase of a long term exercise. In this condition lipolysis in adipose tissue and in muscle-TG is insufficiently up- regulated to result in enhanced FA supply. The result will be that the rate of FA oxidation exceeds the rate at which FAs are mobilised, leading to a fall in plasma FA and intracellular FA in muscle. As a consequence, the use of $\mathrm{CHO}$ from glycogen must be increased to cover the increased energy demand. ${ }^{[17,54-56]}$

\section{Techniques to Improve FA Oxidation}

Since the storage of $\mathrm{CHO}$ in the form of glycogen is limited, the ability to perform high intensity exercise will be decreased with progressive glycogen depletion. ${ }^{[57]}$ Any adaptation leading to an increased capacity to utilise FA for ATP resynthesis will lead to a sparing of endogenous $\mathrm{CHO}$ with the consequence that endurance capacity may be improved. Theoretically there may be a few interventions which potentially increase plasma FA levels and up-regulate the mechanisms involved in transport and oxidation of FA.

\subsection{Endurance Training}

Endurance training has been observed to result in a number of structural and metabolic adaptations which favour FA oxidation. The capillary density of muscle tissue increases which augments the exchange surface area, promotes blood flow and thus the delivery of oxygen and substrates. ${ }^{[18,58]}$ Within skeletal muscle there is an increased mitochondrial volume as well as oxidative enzyme activity. ${ }^{[4,58-62]}$ As a result, trained muscles are able to oxidise more substrate ${ }^{[18]}$ which is also expressed in an increased oxygen consumption at maximal exercise intensities. ${ }^{[59,61]}$ Trained muscles store more intracellular fat and also express a higher LPL activity, which will favour the maximising of FA flux to the mitochondria. ${ }^{[8,9,58,63-65]}$ This may enhance the capacity to utilise intramuscular TG as fue ${ }^{[3,35,36,60,61,63]}$ while using less blood-borne FA. The advantage of a shift from extracellular to intracellular stores of $\mathrm{FA}^{[66,67]}$ is that potential barriers in overall FA utilisation, such as the endothelium and the sarcolemma, are irrelevant when intracellular TG is utilised. Thus, training enhances total FA oxidation by increasing intramuscular fat 
storage and by increasing the maximal FA flux. Along with this, endogenous $\mathrm{CHO}$ stores will be conserved, prolonging the time-period during which intense exercise can be performed.

\subsection{Caffeine Ingestion}

Caffeine affects muscle, adipose and central nervous tissue by indirectly mediating the level of cyclic adenosine monophosphate (cAMP) and its related calcium release from the intracellular storage sites. ${ }^{[68]}$ This effect is initiated by binding of catecholamines to beta-receptors of cell membranes, thereby enhancing the activity of the enzyme adenylate cyclase which catalyses the formation of cAMP from ATP. Caffeine has been observed to enhance plasma noradrenaline (norepinephrine ${ }^{[69]}$ and adrenaline (epinephrine) levels. ${ }^{69-74]}$ Additionally, caffeine inhibits phosphodiesterase which degrades cAMP. In this way caffeine increases cAMP half-life. ${ }^{[75,76]}$ An increase in the cAMP level enhances lipolysis. ${ }^{[77]}$ However, the notion that caffeine affects lipolysis via adrenaline has been challenged. Chesley et al. ${ }^{[78]}$ infused epinephrine to a concentration comparable with the physiological levels after caffeine ingestion and did not observe any effect on plasma FA. Nevertheless, caffeine has been observed to enhance plasma FA in many studies. ${ }^{[71,74,79,80-100]}$

Interestingly, an increased fat oxidation (as assessed by respiratory gas exchange) and reduced glycogen degradation were observed in only a few of these studies. ${ }^{[83,84,86,101]}$ This may be explained by the fact that the caffeine-induced elevation of FA simply comes on top of the relatively high, exercise-induced increase in FA, which already maximises FA delivery for uptake across the epithelium. These data also indicate that the performance-enhancing effects of caffeine ${ }^{[66,70-72,102,103]}$ are most probably related to effects on the central nervous system rather than to effects on fat oxidation and glycogen sparing. Recently it has been shown that caffeine decreases malonyl CoA in skeletal muscle. ${ }^{[104]}$ This may help explain why caffeine induces increased FA oxidation when ingested in resting conditions, but not during exer- cise when malonyl CoA levels in muscle cells are already appreciably lower, due in part to the downregulation of insulin levels.

There are reasons to hypothesise that caffeine ingestion may indirectly also counteract its effect on lipolysis and subsequent FA oxidation during exercise. Increased liver glycogen breakdown and plasma lactate levels have been observed after caffeine ingestion, ${ }^{69,72,102,105-109]}$ and lactate is known to be a strong inhibitor of lipolysis. Thus caffeine might also exert depressing effects on FA oxidation in exercising muscle cells.

\subsection{L-Carnitine Ingestion}

Carnitine is synthesised mainly in the liver, kidney and brain, but not in muscle. ${ }^{[110]}$ Carnitine is also obtained from the diet, especially from red meat. After ingestion with diet or hepatic formation, L-carnitine is released into the circulation and is taken up by muscle. Small quantities are lost daily from the body via urine and stool. In healthy individuals there is a balance between daily synthesis and loss. The primary function of L-carnitine is the transfer of long chain FA across the mitochondrial membrane. ${ }^{[111]}$ It has been hypothesised that increased availability of L-carnitine will increase the capacity to transport FA into mitochondria as well as subsequent oxidation. If true, this would be of significant benefit to the endurance athlete or to individuals wishing to increase their lean body mass by reducing adipose tissue fat.

In vitro, the addition of L-carnitine to an incubation medium has been shown to markedly enhance long chain FA oxidation of isolated mitochondria. ${ }^{[111]}$ In vivo, oral L-carnitine has been observed to increase plasma L-carnitine concentrations, but uptake in muscle remained unchanged. ${ }^{[112]}$ This fits well with the observation that L-carnitine is taken up by muscle against a concentration gradient - plasma 40 to $60 \mu \mathrm{mol} / \mathrm{L}$ muscle 3 to $4 \mathrm{mmol} / \mathrm{L} .{ }^{[113]}$ This gradient is so large that even a substantial oral intake would not result in a measurable change. There are no indications that heavy exercise results in an increased loss of carnitine from the body. Accordingly, no difference 
in resting carnitine levels has been observed between trained and untrained individuals. ${ }^{[14]}$ These data, as well as those of other recent well controlled studies, ${ }^{[115-118]}$ fail to show an effect of L-carnitine supplementation on FA oxidation by muscle during exercise.

\subsection{Medium Chain Triglyceride (TG) Ingestion}

MCTs predominantly contain FAs with a chain length of 6 to 10. ${ }^{[119]}$ Because of their relatively small molecular size, these medium chain fatty acids (MCFA) have several physical characteristics which distinguish them from long chain fatty acids (LCFA). MCFAs are more soluble compared with LCFAs and they have a lower melting point which makes them liquid at room temperature. Whereas LCTs are strong inhibitors of gastric emptying, when added to $\mathrm{CHO}$, MCTs are emptied very rapidly. ${ }^{[120]}$ MCTs require less bile and pancreatic juices for digestion, which results in both a faster and a more complete hydrolysis of MCT. Indeed, MCTs are absorbed almost as fast as glucose. ${ }^{[119]}$

After absorption into the intestinal mucosa, LCFAs are esterified into TGs which will be incorporated into chylomicrons. Via the slow lymph system these chylomicrons will finally reach the systemic circulation. On the other hand, MCFA will directly enter the systemic circulation through the portal vein. As a result, the process of digestion and absorption of LCT typically takes 3 to 4 hours, whereas MCFA may appear in the circulation within several minutes. ${ }^{[121]}$ At the tissue level, there are also differences between LCFA and MCFA. To cross the inner mitochondrial membrane, LCFAs are dependent on carnitine palmitoyltransferase I, whereas MCFAs are less dependent on this transport system. These characteristics of MCT have lead to the suggestion that MCT could be a valuable energy source during exercise, or as a pre-exercise meal in order to increase the FA availability at the onset of exercise and to 'spare' muscle glycogen.

One of the first reports on the effects of preexercise MCT ingestion in humans was a study by Ivy et al. ${ }^{[122]}$ in which 10 well trained men ingested 30g of MCT an hour before commencing a 60-minute exercise bout at $70 \%$ of $\mathrm{VO}_{2 \max }$. The most obvious effect of the MCT ingestion was the rise in circulating ketone bodies acetoacteate and $\beta$ hydroxybutyrate. However, the pre-exercise MCT ingestion had no effect on circulating FA levels or the rates of fat oxidation. These authors also reported severe gastrointestinal problems when more than MCT 50g was ingested and suggested that the maximum amount of MCT that can tolerated by most athletes was about $30 \mathrm{~g} .{ }^{122]}$

Similar results were obtained in a study by Décombaz et al. ${ }^{[123]}$ who had participants exercise for 60 minutes at $60 \%$ of $\mathrm{VO}_{2 \max }$ after the ingestion of MCT 25g. Rates of $\mathrm{CHO}$ and fat oxidation during exercise as well as muscle glycogen breakdown were unaffected by MCT ingestion. ${ }^{[123]}$ Satabin et al. ${ }^{[124]}$ fed participants $45 \mathrm{~g}$ of MCT or LCT an hour before exercise and found that, compared with fasting, there were no changes in substrate utilisation nor exercise time to exhaustion at a workload eliciting $60 \%$ of $\dot{\mathrm{VO}}_{2 \max }$. Recently Horowitz et al. ${ }^{[125]}$ hypothesised that MCT ingestion could be beneficial during intense exercise $\left(>80 \%\right.$ of $\mathrm{VO}_{2 \max }$ ) where FA availability is normally limiting because of a decreased rate of lipolysis. In order to test this hypothesis they fed participants MCT $25 \mathrm{~g}$ an hour before a 30-minute exercise bout at $85 \%$ of $\mathrm{VO}_{2 \max }$. Although ingestion of MCT resulted in elevated levels of circulating ketone body, there was no effect on the rate of fat oxidation, or the rate of glycogen breakdown.

Massicotte et al. ${ }^{[126]}$ were the first group to investigate the effects of MCT ingestion during exercise. Using ${ }^{13} \mathrm{C}$-labelling techniques, they compared the oxidation of MCT with that of glucose during 2 hours of exercise at $65 \%$ of $\mathrm{VO}_{2 \max }$. They found that the contribution to total energy requirements during exercise was similar between the 2 interventions (MCT $119 \pm 31$ vs glucose 140 $\pm 36 \mathrm{kcal})$. More recently, Jeukendrup and coworkers investigated the effects of a combination of $\mathrm{CHO}$ and MCT ingestion during 3 hours of exercise at $57 \%$ of $\dot{\mathrm{V}}_{2 \max }$ in well trained cyclists [127] Participants received a bolus of $4 \mathrm{ml} / \mathrm{kg}$ body mass 
at the start and $2 \mathrm{ml} / \mathrm{kg}$ every 20 minutes during exercise of either a $15 \% \mathrm{CHO}$ solution (total $214 \mathrm{~g}$ ), an equicaloric CHO-MCT solution (149g of CHO, $29 \mathrm{~g}$ of MCT), CHO plus MCT (214g of CHO plus $29 \mathrm{~g}$ of MCT) or $29 \mathrm{~g}$ of MCT in water. In order to estimate the rates of ingested MCT oxidation, a $\left[{ }^{13} \mathrm{C}\right]$ trioctanoate tracer was added to the MCT oil. When MCT was co-ingested with $\mathrm{CHO}$, approximately $70 \%$ of the amount ingested was oxidised during the second hour of exercise, compared with only $33 \%$ when the MCT was ingested alone. Towards the end of the exercise bout, the rates of ingested MCT oxidation reached $0.12 \mathrm{~g} / \mathrm{min}$, which approached the rates of ingestion. Even so, the contribution of ingested MCT to total energy expenditure only reached a maximum of $7 \%$. Although the precise mechanism for the accelerated oxidation of MCT when they were co-ingested with $\mathrm{CHO}$ is not known, these workers speculated that it may have been due to the accelerated entrance of MCT into the systemic circulation. Whatever the mechanism, the total rates of $\mathrm{CHO}$ and fat oxidation were unaffected by MCT ingestion.

In a separate study, Jeukendrup et al. ${ }^{[128]}$ examined the effects of MCT ingestion on the rates of muscle glycogen utilisation during 180 minutes of exercise at $57 \%$ of $\dot{\mathrm{VO}}_{2 \max }$. In agreement with the results from their previous study, ${ }^{[127]}$ MCT ingestion had no effect on the rates of total CHO oxidation, nor the rates of muscle glycogen utilisation. MCT ingestion was also found to have no effect on CHO utilisation even when individuals commenced exercise with low muscle glycogen content. ${ }^{[129]}$

To date, only one study has reported a beneficial effect of MCT ingestion on metabolism and performance. Van Zyl et al. ${ }^{[130]}$ had 6 trained individuals ingest a random order of either a $10 \% \mathrm{CHO}$ solution, a $4.3 \%$ MCT suspension or a combination of MCT plus $\mathrm{CHO}$ during 2 hours of submaximal exercise $\left(60 \%\right.$ of $\left.\dot{\mathrm{VO}}_{2 \max }\right)$ which was immediately followed by a simulated $40 \mathrm{~km}$ time-trial. The amount of MCT ingested throughout the trial was $86 \mathrm{~g}$. Not only were the large $(\approx 30 \mathrm{~g} / \mathrm{h})$ doses of MCT tolerated by their participants, but the addi- tion of MCT to a $\mathrm{CHO}$ solution improved $40 \mathrm{~km}$ time-trial performance by $2.5 \%$ compared with $\mathrm{CHO}$ alone. These authors attributed the enhanced performance to the larger doses of MCT ingested compared with previous studies. ${ }^{[130]}$ However, employing a similar experimental design during which MCT $85 \mathrm{~g}$ was co-ingested with $\mathrm{CHO}$, Jeukendrup et al. ${ }^{[131]}$ found no significant difference in the time to complete a set amount of work $(271 \mathrm{~kJ})$ when MCT was added to $\mathrm{CHO}$ or when only CHO was consumed. ${ }^{[131]}$ In that study gastrointestinal cramping was more often reported when MCT were ingested than with carbohydrate. Interestingly, both studies ${ }^{[130-131]}$ found that MCT ingestion alone reduced performance compared with CHO. Jeukendrup et al. ${ }^{[131]}$ also reported impaired performance with MCT ingestion when compared with placebo (water).

In conclusion, the ingestion of small $(10 \mathrm{~g} / \mathrm{h})$ amounts of MCT have no major effects on FA metabolism, nor do they improve exercise performance. Although the ingestion of larger $(30 \mathrm{~g} / \mathrm{h})$ amounts may enhance exercise capacity, such doses are likely to produce gastrointestinal problems in most athletes which would be expected to be detrimental to performance.

\subsection{Long Chain TG Ingestion}

Compared with MCT, LCTs are a relatively poor source of energy for the exercising muscles. After ingestion, LCTs are emulsified by bile salts and subsequently hydrolysed by the action of pancreatic lipase. They are then transported across the intestinal wall where chylomicrons are formed in the epithelial wall of the intestine. From here, they will slowly enter the systemic circulation. LCT has to be hydrolysed by LPL before LCFA can be delivered to extra-hepatic tissues including the muscle.

Satabin et al. ${ }^{[124]}$ investigated the effects LCT versus MCT ingestion in 9 healthy individuals who consumed isocaloric (400 kCal) amounts of these test solutions 1 hour before an exhaustive exercise bout at $60 \%$ of $\mathrm{VO}_{2 \max }$. The ingested LCT was oxidised to a lesser extent than the MCT ( $9 v s 43 \%$ of 
amount ingested), but submaximal exercise times were not significantly different (108 vs 115 minutes for MCT and LCT, respectively). Ivy et al. ${ }^{[122]}$ also fed participants LCT 1 hour before exercise and observed no differences in serum FA levels but a large increase in the serum TG levels. However, despite these different metabolic responses, the ingestion of LCT had no effect on either carbohydrate or fat oxidation rates compared with MCT.

\subsection{Fat Infusion}

In order to study the effects of elevated FA concentrations on substrate metabolism and exercise performance, several studies have infused lipid emulsions or injected heparin in an attempt to elevate the circulating levels of FA. Costill et al. ${ }^{[132]}$ injected participants with $2000 \mathrm{U}$ of heparin 30 minutes before exercise and $\approx 4$ hours after consumption of a fatty meal. They reported that the elevated plasma FA significantly decreased the rate of muscle glycogen breakdown during 30 minutes of treadmill exercise at $70 \%$ of $\dot{\mathrm{VO}}_{2 \max }$ compared with glucose ingestion. In a similar study from the same lab, Vukovich et al. ${ }^{[133]}$ found a similar reduction $(\approx 40 \%)$ in muscle glycogen breakdown after a lipid emulsion was infused followed by injection of heparin. Dyck et al. ${ }^{[134]}$ infused a lipid emulsion (Intralipid) with heparin during 15 minutes of intense exercise (cycling at $85 \%$ of $\mathrm{VO}_{2 \max }$ ) and found that muscle glycogen utilisation was $44 \%$ lower after the infusion compared with control values. Interestingly, in all of the studies reported so far, less glycogen was utilised during the early stages of exercise when FA levels were elevated at the start of exercise. However, it is feasible that the observed effects are not the result of 'glycogen sparing' per se, but rather an accelerated rate of glycogenolysis in the 'control' trials where typically plasma FFAs are very low $(<0.2 \mathrm{mmol} / \mathrm{L})$. In support of this contention, Ravussin et al. ${ }^{[135]}$ reported increased rates of fat oxidation during the first 30 minutes of exercise at $44 \%$ of $\mathrm{VO}_{2 \max }$ when a lipid emulsion plus heparin (500 U/h IV) was infused, an effect which disappeared after $30 \mathrm{~min}$ - utes of exercise, at which time the rates of carbohydrate and fat oxidation were comparable with a control trial.

At present it is not known whether athletes should aim to commence exercise with elevated levels of plasma FFA or try to prevent these levels from falling too low. The procedure of infusing a lipid emulsion in combination with heparin seems to be impractical and unrealistic in most sports and is also banned by the doping regulations of the International Olympic Commission.

\subsection{Fasting}

In rats, short term fasting increases lipolysis and raises levels of circulating plasma FFA which results in increased endurance performance. ${ }^{[136,137]}$ In humans, however, no such effects have been observed. ${ }^{[138]}$ On the contrary. Fasting may result in decreased muscle glycogen levels which in turn decrease rather than improve endurance performance. Loy et al. ${ }^{[139]}$ showed that a 24-hour fast reduced pre-exercise muscle glycogen content and blood glucose concentrations and impaired subsequent exercise time to exhaustion by 20 to $25 \%$. Thus, although fasting increases the availability of FFA and the rates of fat oxidation during exercise, such perturbations do not have a positive effect on subsequent exercise performance, largely due to a reduction in endogenous glycogen stores.

\section{Effects of High Fat Diets on Exercise Performance and Metabolism}

\section{1 Short Term Exposure to High Fat Diets}

The concept that alteration of an individual's habitual diet several days prior to exercise can modify patterns of fuel substrate utilisation and impact on subsequent performance is not new. Christensen and Hansen ${ }^{[140]}$ were probably the first to show that, if individuals were exposed to a high fat diet (94\% MJ) for just 3 days, subsequent endurance time to exhaustion on a cycle ergometer was significantly shorter compared with when a high CHO diet ( $83 \%$ MJ) was consumed ( 88 vs 210 minutes for the high fat and high $\mathrm{CHO}$ diets, re- 
Table I. Effects of short term (<7-day) dietary exposure to a high fat diet on submaximal exercise capacity and fuel substrate oxidation

\begin{tabular}{|c|c|c|c|c|c|c|c|}
\hline $\begin{array}{l}\text { Study } \\
\text { sample }\end{array}$ & Time (days) & Fat (\%) & $\mathrm{CHO}(\%)$ & Exercise task & Time (min) & RER & Reference \\
\hline \multirow[t]{2}{*}{$7 \mathrm{~T}$} & 1 & 68 & 16 & Time to cycle $1600 \mathrm{~kJ}$ & $139.3^{\mathrm{a}}$ & 0.82 & 146 \\
\hline & 1 & 5 & 83 & Time to cycle $1600 \mathrm{~kJ}$ & 117.1 & $0.89^{b}$ & \\
\hline \multirow[t]{2}{*}{6 UT } & 3 & 46 & 5 & Cycle to fatigue at $75 \% \mathrm{VO}_{2 \max }$ & 57 & 0.79 & 141 \\
\hline & 3 & & 82 & Cycle to fatigue at $75 \% \mathrm{VO}_{2 \max }$ & $167^{b}$ & 0.91 & \\
\hline \multirow[t]{2}{*}{3 UT } & 3 & 94 & 4 & Cycle to exhaustion at $176 \mathrm{~W}$ & 88 & & 140 \\
\hline & 3 & 3 & 83 & Cycle to exhaustion at $176 \mathrm{~W}$ & $210^{\mathrm{b}}$ & & \\
\hline \multirow[t]{2}{*}{7 UT } & 4 & 76 & & Run to fatigue at $70 \% \dot{\mathrm{VO}}_{2 \max }$ & 64 & 0.85 & 142 \\
\hline & 4 & & 77 & Run to fatigue at $70 \% \mathrm{VO}_{2 \max }$ & $106^{\mathrm{b}}$ & 0.95 & \\
\hline \multirow[t]{2}{*}{7 UT } & 4 & 76 & 11 & Run to fatigue at $70 \% \mathrm{VO}_{2 \max }$ & 106 & & 143 \\
\hline & 4 & 10 & 77 & Run to fatigue at $70 \% \mathrm{VO}_{2 \max }$ & $61.5^{\mathrm{b}}$ & & \\
\hline \multirow[t]{2}{*}{20 UT } & 5 & 69 & 5 & Cycle at $65 \% \mathrm{VO}_{2 \max }$ & 25 & 0.81 & 145 \\
\hline & & 8 & 75 & Cycle at $65 \% \mathrm{VO}_{2 \max }$ & 25 & 0.92 & \\
\hline \multirow[t]{2}{*}{$5 \mathrm{~T}$} & 7 & 38 & 50 & Run to fatigue at $75-80 \% \mathrm{VO}_{2 \max }$ & $91.2^{\mathrm{a}}$ & 0.91 & 144 \\
\hline & 7 & 15 & 73 & Run to fatigue at $75-80 \% \mathrm{VO}_{2 \max }$ & 75.8 & 0.91 & \\
\hline
\end{tabular}

a Fat diet significantly greater than carbohydrate, $p<0.05$.

b Carbohydrate diet significantly greater than fat, $\mathrm{p}<0.05$.

Abbreviations: $\mathrm{CHO}=$ carbohydrate; $\mathrm{RER}=$ respiratory exchange ratio; $\mathrm{T}=$ endurance trained; $\mathrm{TT}=$ time-trial; $\mathrm{UT}=\mathrm{untrained} ; \mathrm{VO} \mathrm{O}_{2 \mathrm{max}}=$ maximum oxygen uptake.

spectively; table I). The high fat diet consumed by the participants in that investigation was, however, extreme and likely to have been severely protein deficient. Nevertheless, Bergstrom et al. ${ }^{[141]}$ subsequently reported that intermittent exercise time to fatigue was impaired by $66 \%$ after 3 days of a less severe high fat diet (54\% MJ), compared with when individuals consumed a high $\mathrm{CHO}$ diet similar in composition to that chosen in the study of Christensen and Hansen. ${ }^{[140]}$ The magnitude of the decline in endurance cycling capacity reported in these early investigations after just 3 days exposure to high fat diets is similar to that found by Galbo et al. ${ }^{[142]}$ and Johannessen et al. ${ }^{[143]}$ in participants who performed treadmill exercise to exhaustion after 4 to 5 days of either high fat $(76 \% \mathrm{MJ})$ or high $\mathrm{CHO}(77 \% \mathrm{MJ})$ diets; in all cases, exercise time to exhaustion was reduced by at least $40 \%$ (table I).

The only study to find a beneficial effect of short term exposure to a high fat diet on endurance capacity is that of Muoio et al. ${ }^{[144]}$ This study had 6 well trained runners consume either their habitual diet (61\% MJ from $\mathrm{CHO}, 24 \%$ fat), a 'high fat' diet (50\% MJ CHO, 38\% MJ fat), or a high $\mathrm{CHO}$ diet (73\% MJ CHO, $15 \% \mathrm{MJ}$ fat) for 7 days followed by a maximal treadmill test and a prolonged run to exhaustion at 75 to $85 \%$ of $\mathrm{VO}_{2 \max }$. Interestingly $\dot{\mathrm{VO}}_{2 \max }$ was significantly higher after the high fat compared with both the individuals' habitual diets and the high $\mathrm{CHO}$ diet (66.4 vs 63.7 vs $59.6 \mathrm{ml} / \mathrm{kg} / \mathrm{min}$, respectively; $\mathrm{p}<0.05$ ). Additionally, 5 participants ran on average $32 \%$ longer after the high fat diet compared with their habitual diet, and 20\% longer compared with the high $\mathrm{CHO}$ diet (both $\mathrm{p}<0.05$; table I). However, the results of this study should be interpreted with caution. First, the order of presentation of the dietary treatments was not randomised, but assigned as normal diet, 'high fat' diet and high CHO diet for all participants. Secondly, there was considerable overlap in absolute macronutrient content between the 3 diets, effectively precluding a comparison of treatments. Furthermore, the 'high fat' diet was lower in terms of both absolute and relative fat content compared with the diets typically used in fat adaptation studies. In fact, the 'high fat' diet was similar in composition to that regularly consumed by many athletes. ${ }^{[147]}$ Finally, the mechanism by which performance was improved after the 'high fat' diet is not easy to determine, as RER values 
Table II. Effects of long term (>7-day) dietary exposure to a high fat diet on submaximal exercise capacity and fuel substrate oxidation

\begin{tabular}{|c|c|c|c|c|c|c|c|}
\hline $\begin{array}{l}\text { Study } \\
\text { sample }\end{array}$ & Time (days) & Fat $(\% \mathrm{MJ})$ & $\mathrm{CHO}(\% \mathrm{MJ})$ & Exercise task & Time (min) & RER & Reference \\
\hline \multirow[t]{2}{*}{$5 \mathrm{~T}$} & 10 & 65 & 15 & 150 min at $70 \% \mathrm{VO}_{2 \max }$ then $20 \mathrm{~km} \mathrm{TT}$ & 29.5 & $0.78^{\mathrm{a}}$ & 149 \\
\hline & 10 & 15 & 65 & 150 min at $70 \% \mathrm{VO}_{2 \max }$ then $20 \mathrm{~km}$ TT & 30.9 & 0.81 & \\
\hline \multirow[t]{4}{*}{$5 \mathrm{~T}$} & 14 & 67 & 7 & Cycle to fatigue at $60 \% \mathrm{VO}_{2 \max }$ & $79.7^{\mathrm{a}}$ & $0.87^{\mathrm{a}}$ & 148 \\
\hline & 14 & 12 & 74 & Cycle to fatigue at $60 \% \mathrm{VO}_{2 \max }$ & 42.5 & 0.92 & \\
\hline & 14 & 67 & 7 & Cycle to fatigue at $\approx 90 \% \mathrm{VO}_{2 \max }$ & 8.3 & 1.07 & \\
\hline & 14 & 12 & 74 & Cycle to fatigue at $\approx 90 \% \mathrm{VO}_{2 \max }$ & 12.5 & 1.15 & \\
\hline \multirow[t]{4}{*}{4 UT } & 14 & 60 & 24 & Intermittent cycle/run at $53 \% \dot{\mathrm{VO}}_{2 \max }$ & 270 & & 152 \\
\hline & & 9 & 83 & Intermittent cycle/run at $51 \% \mathrm{VO}_{2 \max }$ & 261.5 & & \\
\hline & & 60 & 24 & Intermittent cycle/run at $70 \% \mathrm{VO}_{2 \max }$ & 161.5 & & \\
\hline & & 9 & 83 & Intermittent cycle/run at $70 \% \mathrm{VO}_{2 \max }$ & 188.5 & & \\
\hline \multirow[t]{2}{*}{$5 \mathrm{~T}$} & 28 & 85 & 2 & Cycle to fatigue at $64 \% \mathrm{VO}_{2 \max }$ & 147 & 0.72 & 150 \\
\hline & 28 & 28 & 55 & Cycle to fatigue at $64 \% \mathrm{VO}_{2 \max }$ & 151 & 0.83 & \\
\hline \multirow[t]{2}{*}{10 UT } & 49 & 62 & 21 & Cycle to fatigue at $70 \% \mathrm{VO}_{2 \max }$ & 65.2 & 0.82 & 151 \\
\hline & 49 & 20 & 65 & Cycle to fatigue at $70 \% \mathrm{VO}_{2 \max }$ & $102.4^{\mathrm{b}}$ & 0.88 & \\
\hline
\end{tabular}

a Fat diet significantly greater than carbohydrate, $p<0.05$.

b Carbohydrate diet significantly greater than fat, $\mathrm{p}<0.05$.

Abbreviations: $\mathrm{CHO}=$ carbohydrate; $\mathrm{RER}=$ respiratory exchange ratio; $\mathrm{T}=$ endurance trained; $\mathrm{TT}=$ time-trial; $\mathrm{UT}=\mathrm{untrained} ; \mathrm{VO}_{2} \mathrm{max}=$ maximum oxygen uptake.

during submaximal exercise were unaffected by either of the dietary manipulations.

To specifically investigate the effects of short term exposure to high fat diets on substrate metabolism during exercise, Jansson and Kaijser ${ }^{[145]}$ studied 20 untrained individuals after 5 days on a high fat diet (69\% MJ) followed by 5 days on a high $\mathrm{CHO}$ diet $(75 \% \mathrm{MJ})$. The high fat diet significantly reduced resting muscle glycogen content compared with the high CHO diet [44 vs $102 \mathrm{mmol} / \mathrm{kg}$ wet weight $(\mathrm{ww})]$. There was also a strong trend for resting muscle TG content to be higher after the high fat compared with the high $\mathrm{CHO}$ diet (91 vs $50 \mathrm{mmol} / \mathrm{kg}$ dry weight), although this difference was not statistically significant, possibly due to the large variation in the content of intracellular fat found in muscle biopsy samples. During 25 minutes of moderate intensity cycling there was an increased extraction of FFA by muscle, but no consistent effect of diet on the rates of working muscle glycogen utilisation. Based on RER values (table $1)$, the relative contribution from fat to oxidative metabolism increased by $37 \%$ after the high fat diet.

In summary, the consumption of a high fat diet for 3 to 7 days impairs moderate intensity cycle and run time to exhaustion in untrained, healthy individuals. Such regimes also reduce resting muscle glycogen content compared with high $\mathrm{CHO}$ diets, and shift substrate metabolism in favour of lipid oxidation. However, there is no sparing of endogenous glycogen stores during exercise.

\subsection{Long Term Adaptation to High Fat Diets}

On the other hand there is some evidence to suggest that longer ( $>7$-day) periods of adaptation to high fat diets may induce adaptive responses that are fundamentally different to the acute lowering of body $\mathrm{CHO}$ reserves which impair exercise performance after short term exposure to $\mathrm{CHO}$ restricted diets (table II). Indeed, it has been proposed that long term exposure to a high fat diet could eventually induce a reversal of some of the mitochondrial adaptations that favour $\mathrm{CHO}$ oxidation and 'retool' the working muscle to increase its capacity for fat oxidation. ${ }^{[148,153]}$ Although it has been suggested that as long as 20 weeks of exposure should be allowed if humans wish to adapt to high fat diets, ${ }^{[154]}$ such a period is both impractical, and could also pose health problems for athletes (see section 5.3). 
Employing a random cross-over design, Lambert et al. ${ }^{[148]}$ studied the effects of 14 days of either a high fat $(67 \% \mathrm{MJ})$ or a high $\mathrm{CHO}(74 \% \mathrm{MJ})$ diet in 5 trained cyclists. After dietary adaptation, participants undertook a comprehensive battery of physical tests, including a Wingate anaerobic test (WAnT), a ride to exhaustion at $\approx 90 \%$ of $\mathrm{VO}_{2 \max }$ and, following a 30-minute rest, a further ride to volitional fatigue at $60 \%$ of $\mathrm{VO}_{2 \max }$. Although the high fat diet significantly reduced pre-exercise muscle glycogen content to $68 \mathrm{mmol} / \mathrm{kg}$ ww compared with $121 \mathrm{mmol} / \mathrm{kg}$ ww after the high $\mathrm{CHO}$ diet, peak power measured during the WAnT was not significantly different (862 vs $804 \mathrm{~W}$ for the high fat and high $\mathrm{CHO}$ diets respectively). Neither was there an effect of dietary manipulation on the time participants could ride at a work rate eliciting $\approx 90 \%$ of $\dot{\mathrm{VO}}_{2 \max }(8.3 \mathrm{vs} 12.5$ minutes for the high fat and high $\mathrm{CHO}$ trials, respectively). Although failing to attain statistical significance, such variability in work output would be expected to result in vastly different athletic performances. The only effect of the high fat diet was to prolong submaximal endurance time from 42 to 80 minutes (table II), despite significantly lower starting muscle glycogen content ( 32 vs $73 \mathrm{mmol} / \mathrm{kg} \mathrm{ww}$ ). Such increases in endurance were associated with a marked decrease in the average rate of $\mathrm{CHO}$ oxidation (2.2 vs $1.4 \mathrm{~g} / \mathrm{min})$ and a significant increase in the rate of fat oxidation from 0.3 to 0.6 g/min. ${ }^{[148]}$ The results of this study suggest that submaximal exercise capacity can be preserved in spite of low pre-exercise muscle glycogen content.

Further suggestions to support the hypothesis that fatigue in the glycogen depleted state may be delayed in individuals with mitochondrial adaptations favouring an increased capacity for fat oxidation come from the work of Phinney et al., ${ }^{[150]}$ who examined the effects of 28 days of a high fat diet versus a eucaloric diet $(66 \% \mathrm{CHO})$ on cycle time to exhaustion at $63 \%$ of $\dot{\mathrm{VO}}_{2 \max }$ (table II). Despite a $47 \%$ reduction in resting muscle glycogen content (143 vs $76 \mathrm{mmol} / \mathrm{kg} \mathrm{ww}), 3$ individuals rode for an equal or longer time, while 2 rode for less time after the high fat compared with a eucaloric diet. Largely as a result of one participant who rode almost $60 \%$ longer after the high fat diet, the mean time for the 5 individuals was not significantly different after the 2 dietary interventions (147 vs 151 minutes for the eucaloric vs high fat diets, respectively; table II). As the experimental design of this study was flawed by lack of a random, cross-over design, the results need to be interpreted with caution. However, it is impressive that performance was not impaired in all individuals given that pre-exercise muscle glycogen levels were decreased by almost $50 \%$. Of interest was that the increase in the relative contribution from fat to oxidative metabolism during submaximal exercise after 28 days of the high fat diet $(40 \%)$ was similar in magnitude to that found after much shorter periods of dietary adaptation ${ }^{[142,145]}$ suggesting that most of the adaptive responses that facilitate an increased rate of fat oxidation are complete after 7 to 10 days.

Probably the longest exposure to a CHO-restricted diet is the recent investigation of Helge et al. ${ }^{[151]}$ who studied 2 groups of 10 untrained participants who underwent a 49-day endurance-training programme while consuming either a high fat $(62 \% \mathrm{MJ})$ or high $\mathrm{CHO}(65 \% \mathrm{MJ})$ diet. Cycle time to exhaustion at $70 \%$ of $\mathrm{VO}_{2 \max }$ increased by $191 \%$ after the high $\mathrm{CHO}$ diet, but only by $68 \%$ in those individuals who consumed the high fat diet (table II). In order to determine if the impairment in endurance observed after the high fat diet could be reversed, these individuals then switched to the high $\mathrm{CHO}$ diet during the 8 th week of the study and the endurance ride was repeated. After 7 days of CHO loading, the mean performance time improved by only 12 minutes. These authors concluded that a combination of training and a fat-rich diet did not reveal an additive effect on physical performance. Such a conclusion, however, is not convincing. Contrary to the results of numerous other investigations, the endurance-training programme employed failed to elicit any increase in the contribution of fat oxidation to the energy requirements of exercise performed at the same absolute intensity. Furthermore, it is difficult to see 
how the results of this study might have any practical significance to well trained endurance athletes who have elevated concentrations of the mitochondrial enzymes for $\beta$-oxidation compared with their untrained counterparts.

Finally, it has recently been proposed that preparation for ultra-endurance events, should encompass periods of nutritional periodisation. ${ }^{[155]}$ Thus, athletes would train for the majority of the year on a high $\mathrm{CHO}$ diet, adapting to a high fat diet for 7 to 10 days in the 2 weeks before a major event, then CHO loading in the final 2 to 3 days before competition. In order to test this hypothesis, van Zyl et al. ${ }^{[149]}$ recently had 5 well trained cyclists ingest a random order of either a high fat $(65 \% \mathrm{MJ})$ or their habitual diet (fat 29\%, CHO 53\% MJ) for 10 days, followed by 3 days of a high $\mathrm{CHO} \operatorname{diet}(65 \% \mathrm{MJ})$. Participants then undertook a 150 -minute ride at $70 \%$ of $\mathrm{VO}_{2 \max }$, followed by a $20 \mathrm{~km}$ time-trial. During both experiments participants ingested a $\mathrm{CHO}+4.3 \% \mathrm{MCT}$ suspension $10 \mathrm{~g} / 100 \mathrm{ml}$. Adaptation to a high fat diet before $\mathrm{CHO}$ loading in association with the ingestion of $\mathrm{CHO}+\mathrm{MCT}$ during exercise significantly improved $20 \mathrm{~km}$ time-trial performance by $\approx 80$ seconds $(\mathrm{p}<0.05$; table II).

\subsection{Effects of High Fat Diets on Blood Lipid Profiles and Insulin Resistance}

It has been suggested that periods of exposure to high fat diets may have a negative impact on health status. ${ }^{[156,157]}$ Yet, to the best of our knowledge, only one study has examined the effect of a high fat diet on blood lipid profiles in athletes. ${ }^{[149]}$ In that investigation, well trained individuals were fed either a high $\mathrm{CHO}(65 \% \mathrm{MJ})$ or high fat $(65 \%$ MJ) diet for 10 days. Plasma cholesterol, high density lipoprotein cholesterol and serum TG levels were not significantly different after the 2 dietary interventions. Nevertheless, chronic high fat diets are normally associated with increased risk of various diseases, and although endurance training attenuates these risks, ${ }^{[158,159]}$ athletes should limit long term exposure to high fat diets. Short term exposure to high fat diets is also associated with insulin resistance in the liver, resulting in a failure to suppress hepatic glucose output, and an attenuation of liver glycogen synthesis. ${ }^{[160]}$ For these reasons, caution should be exercised when recommending high fat diets to athletes.

\section{Conclusions}

Many strategies have been employed in an attempt to promote fat oxidation, slow the rates of endogenous carbohydrate stores and thereby enhance endurance performance. While ingestion of caffeine in some individuals has been shown to improve endurance capacity, supplementing with Lcarnitine has no effect on rates of FA oxidation, muscle glycogen utilisation or performance. The ingestion of small $(10 \mathrm{~g} / \mathrm{h})$ amounts of MCT have no major effects on FA metabolism, nor do they improve exercise performance. The ingestion of larger $(30 \mathrm{~g} / \mathrm{h})$ amounts are likely to produce gastrointestinal problems in most athletes, which would be expected to be detrimental to performance. While fasting increases the availability of FFA and the rates of fat oxidation during exercise, such perturbations do not have a positive effect on subsequent exercise performance.

With regard to the ingestion of diets rich in fat, the results of several studies show that short term (<7-day) exposure to high fat, low $\mathrm{CHO}$ diets significantly impairs endurance performance. On the other hand, in some well trained athletes, long term (>7-day) adaptation to such diets has been shown to prolong endurance time at fixed, submaximal work rates. However, these results are equivocal and are only of practical relevance to a small and select group of competitive athletes. Regardless of the effects on performance, substrate utilisation during submaximal exercise can be modified substantially by exposure to a high fat diet. Compared with a high $\mathrm{CHO}$ diet, the increase in the relative contribution from fat to oxidative metabolism is typically around $40 \%$ after both short or long term adaptation to a high fat diet. However, adaptation to a high fat diet does not appear to alter the rate of working muscle glycogen utilisation during prolonged, moderate intensity exercise. 
At present, there is insufficient scientific evidence to recommend that athletes 'fat load' during training and before major competitions. However, the hypothesis remains that optimal performance in ultra-endurance events lasting $>6$ hours might still be obtained if an athlete trains for most of the year on a high $\mathrm{CHO}$ diet, then undergoes a short term period of fat adaptation followed by the traditional CHO-loading regimen in the final days before the event. Nutritional periodisation for endurance and specifically ultra-endurance events should aim to enhance the contribution from fat to oxidative energy metabolism, thus potentially sparing endogenous $\mathrm{CHO}$ stores. The effects of such nutritional periodisation on metabolism and performance during ultra-endurance events requires further research before any recommendations are possible.

\section{References}

1. Holloszy JO. Utilization of fatty acids during exercise. In: Taylor AW, Gollnick PD, Green HJ, et al., editors. Biochemistry of exercise VII. Champaign (IL): Human Kinetics Publishers, 1990: 319-27

2. Bjorkman O. Fuel utilization during exercise. In: Bjorkman $\mathrm{O}$, editor. Biochemical aspects of physical exercise. Amsterdam: Elsevier, 1986: 245-60

3. Hoppeler H, Luthi P, Claassen H, et al. The ultrastructure of the normal human skeletal muscle: a morphometric analysis on untrained men, women and well-trained orienteers. Pflugers Arch 1973; 344: 217-32

4. Vusse van der GJ, Reneman RS. Lipid metabolism in muscle. In: Rowell LB, Shepherd JT, editors. Handbook of physiology. New York: Oxford Press, 1996: 952-94

5. Spector AA, Fletcher JE, Ashbrook JD. Analysis of long-chain free fatty acid binding to bovine serum albumin by determination of stepwise equilibrium constants. Biochemistry 1971; 10: 3229-33

6. Camps L, Reina M, Lobera M, et al. Lipoprotein lipase: cellular origin and functional distribution. Am J Physiol 1990; 258: C673-81

7. Groot PHE, Oerlemans MC, Scheek LM. Triglyceridase and phospholipase A1 activities of rat heart lipoprotein lipase: influence of apolipoprotein C-II and C-III. Biochim Biophys Acta 1979; 530: 91-8

8. Kiens B, Lithell H. Lipoprotein metabolism influenced by training-induced changes in human skeletal muscle. J Clin Invest 1989; 83: 558-64

9. Kiens B, Lithell H, Mikines KJ, et al. Effects of insulin and exercise on muscle lipoprotein lipase: activity in man and its relation to insulin action. J Clin Invest 1989; 84: 1124-9

10. Gorski J, Stankiewicz-Choroszucha B. The effect of hormones on lipoprotein lipase activity in skeletal muscles of the rat. Horm Metab Res 1982; 14: 189-91
11. Lithell H, Boberg J. Determination of lipoprotein-lipase activity in human skeletal muscle tissue. Biochim Biophys Acta 1978; 528: 55-68

12. Braun JE, Severson A, Severson DL. Regulation of the synthesis, processing and translocation of lipoprotein lipase. Biochem J 1992; 287: 337-47

13. Heaf DJ, Kaijser L, Eklund B, et al. Differences in heparinreleased lipolytic activity in the superficial and deep veins of the human forearm. Eur J Clin Invest 1977; 7: 195-9

14. Terjung RL, Mackie BG, Dudley GA et al. Influence of exercise on chylomicron triacylglycerol metabolism: plasma turnover and muscle uptake. Med Sci Sports Exerc 1983; 15: 340-7

15. Vusse van der GJ, Glatz JFC, Stam HCG, et al. Fatty acid homeostasis in the normoxic and ischemic heart. Physiol Rev 1992; 72: 881-940

16. Havel RJ, Pernow B, Jones NL. Uptake and release of free fatty acids and other metabolites in the legs of exercising men. $\mathrm{J}$ Appl Physiol 1967; 23: 90-9

17. Romijn JA, Coyle EF, Sidossis LS, et al. Regulation of endogenous fat and carbohydrate metabolism in relation to exercise intensity and duration. Am J Physiol 1993; 265: E380-91

18. Gollnick PD, Saltin B. Fuel for muscular exercise: role of fat. In: Exercise, nutrition and energy metabolism. New York: Macmillan, 1988: 71-88

19. Armstrong DT, Steele R, Altszuler N, et al. Regulation of plasma free fatty acid turnover. Am J Physiol. 1961; 201: 9-15

20. Hagenfeldt L, Wahren J. Metabolism of free fatty acids and ketone bodies in skeletal muscle. In: Muscle metabolism during exercise. New York: Plenum Press, 1971: 153-63

21. Vusse van der GJ, Roemen THM. Gradient of fatty acids from blood plasma to skeletal muscle in dogs. J Appl Physiol 1995; 78: $1839-43$

22. Groot PHE, Scholte HR, Hylsmann WC. Fatty acid activation: specificity, localization and function. In: Advances in lipid research. New York: Academic Press, 1976: 75-119

23. Linssen MCJG, Vork MM, De Jong YF, et al. Fatty acid oxidation capacity and fatty acid-binding protein content of different cell types isolated from rat heart. Mol Cell Biochem 1990; 89: $19-26$

24. Harmon CM, Luce P, Abumrad NA. Labelling of an $88 \mathrm{kDa}$ adipocyte membrane protein by sulpho-N-succinimidyl longchain fatty acids: inhibition of fatty acid transport. Biochem Soc Trans 1992; 20: 811-3

25. Vork MM, Glatz JFC, van der Vusse GJ. On the mechanism of long chain fatty acid transport in cardiomyocytes as facilitated by cytoplasmic fatty acid-binding protein. $\mathrm{J}$ Theor Biol 1993; 160: 207-22

26. Froberg SO, Hultman E, Nilsson LH. Effect of noradrenaline on triglyceride and glycogen concentrations in liver and muscle from man. Metabolism 1975; 24: 119-25

27. Abumrad NA, Tepperman HM, Tepperman J. Control of endogenous triglyceride breakdown in the mouse diaphragm. J Lipid Res 1980; 21: 149-55

28. Barclay JK, Stainsby WN. Intramuscular lipid store utilization by contracting dog skeletal muscle in situ. Am J Physiol 1972; 223: $115-9$

29. Cote C, White TP, Faulkner JA. Intramuscular depletion and fatigability of soleus grafts in rats. Can J Physiol Pharmacol 1988; 66: 829-32

30. Froberg SO. Metabolism of lipids in blood and tissues during exercise. Biochem Exerc Med Sport 1969; 3: 100-13

31. Spriet LL, Heigenhauser GJF, Jones NL. Endogenous triacylglycerol utilization by rat skeletal muscle during tetanic stimulation. J Appl Physiol 1986; 60: 410-5 
32. Gorski J. Muscle triglyceride metabolism during exercise. Can J Physiol Pharmacol 1992; 70: 123-31

33. Essen B, Hagenfeldt L, Kaijser L. Utilization of blood-borne and intramuscular substrates during continuous and intermittent exercise in man. J Physiol 1977; 265: 489-506

34. Essen B. Intramuscular substrate utilization during prolonged exercise. In: Milvy P, editors. The marathon: physiological, medical, epidemiological, and psychological studies. New York: The New York Academy of Sciences, 1977: 30-44

35. Howald H, Hoppeler H, Claassen $\mathrm{H}$, et al. Influences of endurance training on the ultrastructural composition of the different muscle fiber types in humans. Pflugers Arch 1985; 403: 369-76

36. Morgan TE, Short FA, Cobb LA. Effect of long-term exercise on skeletal muscle lipid composition. Am J Physiol 1969; 216 : 82-6

37. Saltin B, Kiens B, Savard G. A quantitative approach to the evaluation of skeletal muscle substrate utilization in prolonged exercise. In: Bjorkman O, editor. Biochemical aspects of physical exercise. Amsterdam: Elsevier, 1986: 235-44

38. Abernethy PJ, Thayer R, Taylor AW. Acute and chronic responses of skeletal muscle to endurance and sprint exercise. Sports Med 1990; 10: 365-89

39. Gollnick PD. Metabolism of substrates: energy substrate metabolism during exercise and as modified by training. Fed Proc 1985; 44: 353-7

40. Terjung RL, Kaciuba-Uscilko H. Lipid metabolism during exercise: influence of training. Diabetes Metab Rev 1986; 2: $35-51$

41. Wendling PS, Peters SJ, Heigenhauser GJF, et al. Epinephrine infusion does not enhance net muscle glycogenolysis during prolonged aerobic exercise. Can J Appl Physiol 1996; 21: 271-84

42. McDermott JC, Elder GCB, Bonen A. Adrenal hormones enhance glycogenolysis in nonexercising muscle during exercise. J Appl Physiol 1987; 63: 1275-83

43. McDermott JC, Elder GCB, Bonen A. Non-exercising muscle metabolism during exercise. Pflugers Arch 1991; 418: 301-7

44. Mazzeo RS, Marshall P. Influence of plasma catecholamines on the lactate threshold during graded exercise. J Appl Physiol 1989; 67: 1319-22

45. Bonen A, Ness GW, Belcastro AN, et al. Mild exercise impedes glycogen repletion in muscle. J Appl Physiol 1985; 58: 1622-9

46. Ahlborg G, Felig P. Lactate and glucose exchange across the forearm, legs, and splanchnic bed during and after prolonged leg exercise. J Clin Invest 1982; 69: 45-54

47. Ahlborg G, Wahren J, Felig P. Splanchnic and peripheral glucose and lactate metabolism during and after prolonged arm exercise. J Clin Invest 1986; 77: 690-9

48. McGilvery JD, Stark MJ, Foster DW. The use of fuels for muscular work. In: Metabolic adaptation to prolonged physical exercise. Basel: Birkhauser Verlag, 1975: 12-30

49. Hultman E, Harris RC. Carbohydrate metabolism. In: Poortmans JR, editor. Principles of exercise biochemistry. Basel: Karger, 1988: 78-119

50. Brady PS, Ramsay RR, Brady LJ. Regulation of the long-chain carnitine acyltransferases. FASEB J 1993; 7: 1039-44

51. McGarry JD, Mills SE, Long CS, et al. Observations on the affinity for carnitine, and malonyl-CoA sensitivity, of carnitine palmitoyltransferase $\mathrm{I}$ in animal and human tissues. Biochem J 1983; 214: 21-8

52. Saggerson D, Ghadiminejad I, Awan M. Regulation of mitochondrial carnitine palmitoyltransferase from liver and extrahepatic tissues. Adv Enzyme Regul 1992; 32: 285-306
53. Winder WW, Arogyasami J, Barton RJ, et al. Muscle malonylCoA decreases during exercise. J Appl Physiol 1989; 67: 2230-3

54. Lithell H, Orlander J, Schele R, et al. Changes in lipoprotein-lipase activity and lipid stores in human skeletal muscle with prolonged heavy exercise. Acta Physiol Scand 1979; 107: 257-61

55. Newsholme EA. Basic aspects of metabolic regulation and their application to provision of energy in exercise. In: Principles of exercise biochemistry. Basel: Karger, 1988: 40-77

56. Newsholme EA. Application of knowledge of metabolic integration to the problem of metabolic limitations in sprints, middle distance and marathon running. Principles of exercise biochemistry. Basel: Karger, 1988: 194-211

57. Brouns F. The effect of athletic training and dietary factors on the modulation of muscle glycogen. In: Reilly $\mathrm{T}$, Orne $\mathrm{M}$, editors. The clinical pharmacology of sport and exercise. Amsterdam: Elsevier, 1997: 181-93

58. Gollnick PD, Saltin B. Significance of skeletal muscle oxidative enzyme enhancement with endurance training. Clin Physiol 1982; 2: 1-12

59. Gollnick PD, Ianuzzo CD, King DW. Ultrastructural and enzyme changes in muscles with exercise. In: Saltin B. Advances in experimental medicine and biology. New York: Plenum Press, 1971: 69-86

60. Hoppeler H, Howald H, Concley K, et al. Endurance training in humans: aerobic capacity and structure of skeletal muscle. J Appl Physiol 1985; 59: 320-7

61. Morgan TE, Cobb LA, Short FA, et al. Effects of long-term exercise on human muscle mitochondria. In: Advances in experimental medicine and biology. New York: Plenum Press, 1971: 87-95

62. Baldwin KM, Klinkerfuss GH, Terjung RL, et al. Respiratory capacity of white, red, and intermediate muscle: adaptive response to exercise. Am J Physiol 1972; 222: 373-8

63. Kiens B, Essen-Gustavsson B, Christensen NJ, et al. Skeletal muscle substrate utilization during submaximal exercise in man effect of endurance training. J Physiol 1993; 469: 459-78

64. Saltin B, Astrand PO. Free fatty acids and exercise. Am J Clin Nutr 1993; 57: 752S-8S

65. Nikkila EA, Taskinen R, Rehunen S, et al. Lipoprotein lipase activity in adipose tissue and skeletal muscle of runners: relation to serum lipoproteins. Metabolism 1978; 27: 1661-71

66. Martin III WH, Dalsky GP, Hurley BF, et al. Effect of endurance training on plasma free fatty acid turnover and oxidation during exercise. Am J Physiol 1993; 265: E708-14

67. Jansson E, Kaijser L. Substrate utilization and enzymes in skeletal muscle of extremely endurance-trained men. J Appl Physiol 1987; 62: 999-1005

68. Leijten PAA, Breeman van C. The effects of caffeine on the noradrenaline-sensitive calcium store in rabbit aorta. J Physiol Lond 1984; 357: 327-39

69. Collomp K, Ahmaidi S, Audran M, et al. Effects of caffeine ingestion on performance and anaerobic metabolism during the Wingate test. Int J Sports Med 1991; 12: 439-43

70. Graham TE, Spriet LL. Performance and metabolic responses to a high caffeine dose during prolonged exercise. J Appl Physiol 1991; 71: 2292-8

71. Graham TE, Spriet LL. Metabolic, catecholamine and exercise performance responses to varying doses of caffeine. J Appl Physiol 1995; 78: 867-74

72. Collomp K, Caillaud C, Audran M, et al. Influence de la prise aiguë ou chronique de cafeine sur la performance et les cate- 
cholamines au cours d'un exercice maximal. C R Seances Soc Biol Fil 1990; 184: 87-92

73. Berkowitz BA, Spector S. Effect of caffeine and theophylline on peripheral catacholamines. Eur J Pharmacol 1971; 13: 193-6

74. Spriet LL, MacLean DA, Dyck DJ, et al. Caffeine ingestion and muscle metabolism during prolonged exercise in humans. Am J Physiol 1992; 262: E891-8

75. Beavo JA, Rogers NL, Crofford OB, et al. Effects of xanthine derivatives on lipolysis and on adenosine $3^{\prime}, 5^{\prime}$-monophosphate phosphodiesterase activity. Mol Pharmacol 1970; 6: 597-603

76. Fredholm BB. Are methylxanthine effects due to antagonism of endogenous adenosine? Trends Pharmacol Sci 1980; 1: 129-32

77. Zhang Y, Wells J. The effects of chronic caffeine administration on peripheral adenosine receptors. J Pharmacol Exp Ther 1990; 254: 757-63

78. Chesley A, Hultman E, Spriet LL. Effects of epinephrine infusion on muscle glycogenolysis during intense aerobic exercise. Am J Physiol 1995; 268: E127-34

79. Powers SK, Byrd RJ, Tulley R, et al. Effects of caffeine ingestion on metabolism and performance during graded exercise. Eur J Appl Physiol 1983; 50: 301-7

80. Sasaki H, Maeda J, Usui S, et al. Effect of sucrose and caffeine ingestion on performance of prolonged strenuous running. Int J Sports Med 1987; 8: 261-5

81. Bellet S, Kershbaum A, Aspe J. The effect of caffeine on free fatty acids. Arch Intern Med 1965; 116: 750-2

82. Bellet S, Kershbaum A, Finck EM. Response of free fatty acids to coffee and caffeine. Metabolism 1968; 17: 702-7

83. Costill DL, Dalsky GP, Fink WJ. Effects of caffeine ingestion on metabolism and exercise performance. Med Sci Sports 1978; 10: 155-8

84. Ivy JL, Costill DL, Fink WJ, et al. Influence of caffeine and carbohydrate feedings on endurance performance. Med Sci Sports 1979; 11: 6-11

85. Acheson KJ, Campbell IT, Edholm OG, et al. The measurement of daily energy expenditure: an evaluation of some techniques. Am J Clin Nutr 1980; 33: 1155-64

86. Essig D, Costill DL, Handel van PJ. Effects of caffeine ingestion on utilization of muscle glycogen and lipid during leg ergometer cycling. Int J Sports Med 1980; 1: 86-90

87. Knapik JJ, Jones BH, Toner MM, et al. Influence of caffeine on serum substrate changes during running in trained an untrained individuals. In: Knuttgen HG, Vogel J, Poortmans J, editors. Biochemistry of exercise. Champaign (IL): Human Kinetics Publishers, 1983: 514-9

88. Arogyasami J, Yang HT, Winder WW. Effect of caffeine on glycogenolysis during exercise in endurance trained rats. Med Sci Sports Exerc 1989; 21: 173-7

89. Tarnopolsky MA, Atkinson SA, MacDougall JD. Physiological responses to caffeine during endurance running in habitual caffeine users. Med Sci Sports Exerc 1989; 21: 418-24

90. Dodd SL, Brooks E, Powers SK, et al. The effects of caffeine on graded exercise performance in caffeine naive versus habituated subjects. Eur J Appl Physiol 1991; 62: 424-9

91. Doubt TJ, Hsieh SS. Additive effects of caffeine and cold water during submaximal leg exercise. Med Sci Sports Exerc 1991; 23: $435-42$

92. Galbo H, Holst JJ, Christensen NJ. Glucagon and plasma catecholamine responses to graded and prolonged exercise in man. J Appl Physiol 1975; 38: 70-6
93. Toner MM, Kirkendall DT, Delio DJ, et al. Metabolic and cardiovascular responses to exercise with caffeine. Ergonomics 1982; 25: 1175-83

94. Casal DC, Leon AS. Failure of caffeine to affect substrate utilization during prolonged running. Med Sci Sports Exerc 1985; 17: 174-9

95. Winder WW. Effect of intravenous caffeine on liver glycogenolysis during prolonged exercise. Med Sci Sports Exerc 1986; 18: 192-6

96. Weir J, Noakes TD, Myburgh K, et al. A high carbohydrate diet negates the metabolic effect of caffeine during exercise. Med Sci Sports Exerc 1987; 19: 100-5

97. Bond V, Adams R, Balkissoon B, et al. Effects of caffeine on cardiorespiratory function and glucose metabolism during rest and graded exercise. J Sports Med 1987; 27: 47-52

98. Falk B, Burstein R, Ashkenazi I, et al. The effect of caffeine ingestion on physical performance after prolonged exercise. Eur J Appl Physiol 1989; 59: 168-73

99. Titlow LW, Ishee JH, Riggs CE. Failure of caffeine to affect metabolism during $60 \mathrm{~min}$ submaximal exercise. J Sports Sci 1991; 9: 15-22

100. Engels H-J, Haymes EM. Effects of caffeine ingestion on metabolic responses to prolonged walking in sedentary males. Int J Sport Nutr 1992; 2: 386-96

101. Costill DL, Coyle E, Dalsky G, et al. Effects of elevated plasma FFA and insulin on muscle glycogen usage during exercise. J Appl Physiol 1977; 43: 695-9

102. Anselme F, Collomp K, Mercier B, et al. Caffeine increases maximal anaerobic power and blood lactate concentration. Eur J Appl Physiol 1992; 65: 188-91

103. Pasman WJ, Baak van MA, Jeukendrup AE, et al. The effect of different dosages of caffeine on endurance performance time. Int J Sports Med 1995; 16: 225-30

104. MacLean PS, Winder WW. Caffeine decreases malonyl-CoA in isolated perfused scheletal muscle of rats. J Appl Physiol 1995; 78: 1496-501

105. Richter EA, Garetto LP, Goodman MN, et al. Enhanced muscle glucose metabolism after exercise: modulation by local factors. Am J Physiol 1984; 246: E476-82

106. Sonne B, Galbo H. Carbohydrate metabolism during and after exercise in rats: studies with radioglucose. J Appl Physiol 1985; 59: 1627-39

107. Issekutz B. Effect of epinephrine on carbohydrate metabolism in exercising dogs. Metabolism 1985; 34: 457-64

108. Winder WW. Control of hepatic glucose production during exercise. Med Sci Sports Exerc 1985; 17: 2-5

109. Gaesser GA, Rich RG. Influence of caffeine on blood lactate response during incremental exercise. Int J Sports Med 1985; 6: 207-11

110. Hoppel CL, Davis AT. Inter-tissue relationship in the synthesis and distribution of carnitine. Biochem Soc Trans 1986; 14: 673-4

111. Fritz IB. The metabolic consequences of the effects of carnitine on long-chain fatty acid oxidation. In: Gran FC, editor. Cellular compartimentalization and control of fatty acid metabolism. New York: Academic Press, 1968: 39-63

112. Soop M, Bjorkman O, Cederblad G, et al. Influence of carnitine supplementation on muscle substrate and carnitine metabolism during exercise. J Appl Physiol 1988; 64: 2394-9

113. Engel AG, Rebouche CJ. Carnitine metabolism and inborn errors. J Inherit Metab Dis 1984; 7: 38-43

114. Janssen GME, Scholte HR, Vaandrager-Verduin MHM, et al. Muscle carnitine level in endurance training and running a marathon. Int J Sports Med. 1989; 10: S153-5 
115. Maassen N, Schršder P, Schneider G. Carnitine does not enhance maximum oxygen uptake and does not increase performance in endurance exercise in the range of one hour [abstract]. Int J Sports Med 1995; 15: 375

116. Vukovich MD, Costill DL, Fink WJ. L-carnitine supplementation: effect on muscle carnitine content and glycogen utilization during exercise [abstract]. Med Sci Sports Exerc 1994; 26: $\mathrm{S} 8$

117. Vukovich MD, Costill DL, Fink WJ. Carnitine supplementation: effect on muscle carnitine and glycogen content during exercise. Med Sci Sports Exerc 1994; 26: 1122-9

118. Trappe SW, Costill DL, Goodpaster B, et al. The effects of L-carnitine supplementation on performance during interval swimming. Int J Sports Med 1994; 15: 181-5

119. Bach AC, Babayan VK. Medium-chain triglycerides: an update. Am J Clin Nutr 1982, 36: 950-62

120. Beckers EJ, Jeukendrup AE, Brouns F, et al. Gastric emptying of carbohydrate-medium chain triglyceride suspensions at rest. Int J Sports Med 1992; 13: 581-4

121. Emken EA. Metabolism of dietary stearic acid relative to other fatty acids in human subjects. Am J Clin Nutr 1994; 60 Suppl.: 1023S-8S

122. Ivy JL, Costill DL, Fink WJ, et al. Contribution of medium and long chain triglyceride intake to energy metabolism during prolonged exercise. Int J Sports Med 1980; 1: 15-20

123. Décombaz J, Arnaud MJ, Milon H, et al. Energy metabolism of medium chain triglycerides versus carbohydrate during exercise. Eur J Appl Physiol 1983; 52: 9-14

124. Satabin P, Portero P, Defer G, et al. Metabolic and hormonal responses to lipid and carbohydrate diets during exercise in man. Med Sci Sports Exerc 1987; 19: 218-23

125. Horowitz JF, Mora-Rodriguez R, Coyle EF. The effect of preexercise medium-chain triglyceride ingestion on muscle glycogen utilization during high intensity exercise. Med Sci Sports Exerc 1995; 27: S203

126. Massicotte D, Peronnet F, Brisson GR, et al. Oxidation of exogenous medium-chain free fatty acids during prolonged exercise: comparison with glucose. J Appl Physiol 1992; 73: 1334-9

127. Jeukendrup AE, Saris WHM, Schrauwen P, et al. Metabolic availability of medium chain triglycerides co-ingested with carbohydrates during prolonged exercise. J Appl Physiol 1995; 79: 756-62

128. Jeukendrup AE, Wagenmakers AJM, Brouns F, et al. Effects of carbohydrate $(\mathrm{CHO})$ and fat supplementation on $\mathrm{CHO}$ metabolism during prolonged exercise. Metabolism 1996; 45: 915-21

129. Jeukendrup AE, Saris WHM, Van Diesen R, et al. Effect of endogenous carbohydrate availability on oral medium-chain triglyceride oxidation during prolonged exercise. J Appl Physiol 1996; 80: 949-54

130. Van Zyl CG, Lambert EV, Hawley JA, et al. Effects of mediumchain triglyceride ingestion on carbohydrate metabolism and cycling performance. J Appl Physiol 1996; 80: 2217-25

131. Jeukendrup AE, Thielen JJ, Wagenmakers AJM, et al. Effect of MCT and carbohydrate ingestion on substrate utilization and cycling performance. Am J Clin Nutr 1998; 67: 397-404

132. Costill DL, Coyle EF, Dalsky G, et al. Effects of elevated plasma FFA and insulin on muscle glycogen usage during exercise. $\mathrm{J}$ Appl Physiol 1977; 43: 695-9

133. Vukovich MD, Costill DL, Hickey MS, et al. Effect of fat emulsion infusion and fat feeding on muscle glycogen utilization during cycle exercise. J Appl Physiol 1993; 75: 1513-8
134. Dyck DJ, Putman CT, Heigenhauser JGF, et al. Regulation of fat-carbohydrate interaction in skeletal muscle during intense aerobic cycling. Am J Physiol 1993; 265: E852-9

135. Ravussin E, Bogardus CK, Scheidegger K, et al. Effect of elevated FFA on carbohydate and lipid oxidation during prolonged exercise in humans. J Appl Physiol 1986; 60: 893-900

136. Dohm GL, Tapscott EB, Barakat HA, et al. Influence of fasting on glycogen depletion in rats during exercise. J Appl Physiol 1983; 55: 830-3

137. Koubi HE, Desplanches D, Gabrielle C, et al. Exercise endurance and fuel utilization: a reevaluation of the effects of fasting. J Appl Physiol 1991; 70: 1337-43

138. Ladu MJ. Regulation of lipoprotein lipase in muscle and adipose tissue during exercise. J Appl Physiol 1991; 71: 404-9

139. Loy SF, Conlee RK, Winder WW, et al. Effect of 24-hour fast on cycling endurance time at two different intensities. J Appl Physiol 1986; 61: 654-9

140. Christensen EH, Hansen O. Zur Methodik der respiratorischen Quotientbestimmung in Ruhe und bei Arbeit. III: Arbeitsfähigkeit und Ernährung. Scand Arch Physiol 1939; 81: 160-71

141. Bergstrom J, Hermansen L, Hultman E, et al. Diet, muscle glycogen and physical performance. Acta Physiol Scand 1967; 71: $140-50$

142. Galbo H, Holst JJ, Christensen NJ. The effect of different diets and of insulin on the hormonal response to prolonged exercise. Acta Physiol Scand 1979; 107: 19-32

143. Johannessen A, Hagen C, Galbo H. Proloactin, growth hormone, thyrotropin, 3,5,3'-triiodothryronine, and thryxine responses to exercise after fat-and carbohydrate-enriched diets. J Clin Endocrin Metab 1981; 52: 56-61

144. Muoio DM, Leddy JJ, Horvath PJ, et al. Effect of dietary fat on metabolic adjustments to maximal $\mathrm{V}_{2}$ and endurance in runners. Med Sci Sports Exerc 1994; 26: 81-8

145. Jansson E, Kaijser L. Effect of diet on the utilization of bloodborne and intramuscular substrates during exercise in man. Acta Physiol Scand 1982; 115: 19-30

146. Starling RD, Trappe TA, Parcell AC, et al. Effects of diet on muscle triglyceride and endurance performance. J Appl Physiol 1997; 82: 1185-9

147. Hawley JA, Dennis, Lindsay FH, et al. Nutritional practices of athletes: are they suboptimal? J Sports Sci 1995; 13: S75-S81

148. Lambert EV, Speechly DP, Dennis SC, et al. Enhanced endurance in trained cyclists during moderate intensity exercise following 2 weeks adaptation to a high fat diet. Eur J Appl Physiol 1994; 69: 287-93

149. van Zyl C, Murphy K, Hawley JA, et al. Effects of a high-fat diet prior to carbohydrate loading on metabolism and cycling performance. Eur J Appl Physiol 1998. In press

150. Phinney SD, Bistrian BR, Evans WF. The human metabolic response to chronic ketosis without caloric restriction: preservation of submaximal exercise capacity with reduced carbohydrate oxidation. Metabolism 1983; 32: 769-76

151. Helge JW, Richter EA, Kiens B. Interaction of training and diet on metabolism and endurance during exercise in man. J Physiol 1996; 492: 293-306

152. Pruett EDR. Glucose and insulin during prolonged work stress in men living on different diets. J Appl Physiol 1970; 28: 199-208

153. Conlee RK. Muscle glycogen and exercise endurance: a twentyyear perspective. In: Pandolph KB, editor. Exercise and sport sciences reviews. New York: Macmillan, 1987: 1-28

154. Kronfeld DS. Diet and the performance of racing sled dogs. J Am Vet Med Assoc 1973; 162: 470-3 
155. Hawley JA, Hopkins WG. Aerobic glycolytic and aerobic lipolytic power systems: a new paradigm with implications for endurance and ultraendurance events. Sports Med 1995; 19: 240-50

156. Brouns F, van der Vusse L. Limitations in the role of fat as energy source for physical endurance activities. Br J Nutr 1998; 79: 117-28

157. Jeukendrup AE. Fat metabolism during exercise: a review. In: Aspects of carbohydrate and fat metabolism. Haarlem: De Vrieseborch, 1997: 21-71

158. Sarna S, Kaprio J. Life expectancy of former athletes. Sports Med 1994; 17: 149-51
159. Sternfeld B. Cancer and the protective effect of physical activity: the epidemiological evidence. Med Sci Sports Exerc 1992; 24: 195-209

160. Kraegen EW, Clark PW, Jenkins AB, et al. Development of muscle insulin resistance after insulin resistance in high-fatfed rats. Diabetes 1991; 40: 1397-403

Correspondence and reprints: Dr John A Hawley, Sports Science Institute of South Africa, PO Box 115, Newlands 7725 , South Africa. 